\title{
Jahi McMath, a New Disorder of Consciousness*
}

\author{
Calixto Machadoa
}

\begin{abstract}
In this paper, I review the case of Jahi McMath, who was diagnosed with brain death (BD). Nonetheless, ancillary tests performed nine months after the initial brain insult showed conservation of intracranial structures, EEG activity, and autonomic reactivity to the "Mother Talks" stimulus. She was clinically in an unarousable and unresponsive state, without evidence of self-awareness or awareness of the environment. However, the total absence of brainstem reflexes and partial responsiveness rejected the possibility of a coma. Jahi did not have uws because she was not in a wakefulness state and showed partial responsiveness. She could not be classified as a LIS patient either because Lis patients are wakeful and aware, and although quadriplegic, they fully or partially preserve brainstem reflexes, vertical eye movements or blinking, and respire on their own. She was not in an Mcs because she did not preserve arousal and preserved awareness only partially. The CRS-R resulted in a very low score, incompatible with MCS patients. MCS patients fully or partially preserve brainstem reflexes and usually breathe on their own. mcs has always been described as a transitional state between a coma and uws but never reported in a patient with all clinical BD findings. This case does not contradict the concept of BD but brings again the need to use ancillary tests in BD up for discussion. I concluded that Jahi represented a new disorder of consciousness, non-previously described, which I have termed "reponsive unawakefulness syndrome" (RUS).
\end{abstract}

Keywords: brain death; coma; unresponsive wakefulness syndrome; locked-in syndrome; disorders of consciousness; ancillary tests; EEG; heart rate variability; magnetic resonance imaging

Received: 24/02/2021 Accepted: 07/04/2021

Available online: $23 / 07 / 2021$

How to cite: Machado C. Jahi McMath, a New Disorder of Consciousness. Rev. latinoam. bioet [Internet]. 2021Jul.23 [cited 2021Jul.23];21(1):137-154. Available from: https://revistas.unimilitar. edu.co/index.php/rlbi/article/view/5635

* Research article

a Institute of Neurology and Neurosurgery, Havana, Cuba.

E-mail: braind@infomed.sld.cu

ORCID: https://orcid.org/0000-0002-0539-5844 


\section{Jahi McMath, un nuevo trastorno de la conciencia}

Resumen: En este artículo, revisó el caso de Jahi McMath, quién fue diagnosticada con muerte encefálica (ME). No obstante, exámenes complementarios realizados nueve meses después de la lesión cerebral inicial mostraron conservación de las estructuras intracraneales, actividad en electroencefalografía EEG, y reactividad autonómica a estímulos llamados "Conversación de Madre". Ella estaba clínicamente en un estado sin respuesta a los estímulos, sin evidencia de autoconciencia o conciencia del ambiente. Sin embargo, la ausencia total de reflejos del tronco encefálico y la capacidad de respuesta parcial rechazaron la posibilidad de un coma. Jahi no tenía síndrome de vigilia sin respuesta SVSR porque no estaba en un estado de vigilia y mostró una capacidad de respuesta parcial. Tampoco pudo ser clasificada como paciente LIS porque los pacientes Lis están despiertos y conscientes, y aunque tetrapléjicos, conservan total o parcialmente los reflejos del tronco encefálico, los movimientos oculares verticales $u$ el parpadeo, y respiran por sí mismos. Ella no estaba en un EMc porque no preservaba la excitación y preservaba la conciencia solo parcialmente. La CRS-R dio una puntuación muy baja, incompatible con pacientes de EMC. Los pacientes de EMC preservan total o parcialmente los reflejos del tronco encefálico y, por lo general, respirar por sí solos. El EMC siempre se ha descrito como un estado de transición entre un coma y SVSR pero nunca se ha reportado en paciente con todos los hallazgos clínicos de ME. Este caso no contradice el concepto de ME pero vuelve a plantear la discusión acerca de la necesidad de utilizar exámenes complementarios en ME. Llegué a la conclusión de que Jahi representaba un nuevo trastorno de la conciencia, no descrito anteriormente, que he denominado "síndrome de no despertar con respuesta" (SNDR).

Palabras clave: muerte encefálica; coma; síndrome de vigilia sin respuesta; síndrome de enclaustramiento; trastornos de la conciencia; exámenes complementarios; EEG; variabilidad del ritmo cardíaco; imágenes de resonancia magnética

\section{Jahi McMath, um novo transtorno da consciência}

Resumo: Neste artigo, foi revisado o caso Jahi McMath, que foi diagnosticada com morte encefálica (ME). Contudo, exames complementares realizados nove meses depois da lesão cerebral inicial mostraram conservação das estruturas intracranianas, atividade em eletroencefalografia (EEG) e reatividade autonômica a estímulos chamados "Conversación de Madre". Ela estava clinicamente em um estado sem resposta aos estímulos, sem evidência de autoconsciência ou consciência do ambiente. Contudo, a ausência total de reflexos do tronco encefálico e a capacidade de resposta parcial rejeitaram a possibilidade de um coma. Jahi não tinha síndrome de vigia sem resposta (SVSR), porque não estava em um estado de vigia e mostrou uma capacidade de resposta parcial. Também não pode ser classificada como paciente LIS, porque estes estão acordados e conscientes, e ainda que tetraplégicos, conservam total ou parcialmente os reflexos do tronco encefálicos, os movimentos oculares verticais ou cintilação, e respiram por si próprios. Ela não estava em um EMC porque não preservava a excitação e preservava a consciência somente parcialmente. A CRS-R deu uma pontuação muito baixa, incompatível com pacientes de EMC. Os pacientes de EMC preservam total ou parcialmente os reflexos do tronco encefálico e, em geral, respirar por si só. O EMC sempre foi descrito como um estado de transição entre coma e SVSR, mas nunca foi relatado em paciente com todos os achados clínicos de ME. Esse caso não contradiz o conceito de ME, mas volta a colocar a discussão sobre a necessidade de utilizar exames complementares em ME. Cheguei à conclusão de que Jahi representava um novo transtorno da consciência, não descrito anteriormente, que denominei "síndrome de resposta sem vigília" (SRSV)

Palavras-chave: morte encefálica; coma; síndrome de vigia sem resposta; síndrome de encarceramento; transtornos da consciência; exames complementares; EEG; variabilidade do ritmo cardíaco; imagens de ressonância magnética 


\section{Introduction}

Brain death (BD) has been progressively accepted since the late 1950s. (1-3) Nonetheless, contentious BD cases have recently raised new controversies about its diagnosis, widely covered in the United States (US) and the international press, such as the Jahi McMath case. (4-10) Her situation was a tragedy for her and her family. But the case has caused confusion and qualms about a basic question beyond this sad story: how do we confirm whether a person is dead or alive?

\section{The Story of Jahi McMath (5,7-12)}

Thirteen-year-old Jahi McMath underwent pharyngeal surgery for obstructive sleep apnea at Oakland Children's Hospital on December 9, 2013. Later that evening, she suffered a massive hemorrhage inside her respiratory ways, leading to cardiorespiratory arrest. CPR allowed spontaneous circulation to return, but a significant hypoxic encephalopathy resulted from the event. After two days, the chief of neurology examined her and performed an electroencephalogram (EEG). He diagnosed her with BD. According to the hospital policy, a second physician confirmed the diagnosis, and Jahi McMath was officially declared braindead on December 12, 2013.

As is usually practiced in BD cases, physicians gave a couple of days to Jahi's relatives to consider organ donation, which was finally denied. On December 15 , the hospital told the family that the ventilator would be removed the following morning. The family immediately rejected this possibility and hired an attorney, at which point the hospital agreed to continue with ventilation at least temporarily. A week after the initial event, lawyer Christopher Dolan began to argue the family's wishes to keep Jahi on the ventilator. In a petition to the Alameda Superior County Court, Dolan requested that a physician unaffiliated with the hospital examine Jahi. Evelio Grillo, a judge from the Alameda Superior County Court, appointed an independent specialist, Paul Fisher, chief of neurology at Stanford University's Children Hospital, to examine Jahi McMath. He repeated the earlier examination procedures and also performed a cerebral blood flow study. Both the exam and the study confirmed the diagnosis of $\mathrm{BD}$. At this point, the judge ruled that Jahi McMath was legally dead. Nevertheless, the family and the hospital reached an unusual agreement for her body to be released to her mother, with a ventilator and intravenous fluids.

She was later discharged from the hospital and was moved to New Jersey, where the patients' relatives did not accept either a cardio-respiratory or neurological view of death. She spent most of the next four years in an apartment in New Jersey. She had no spontaneous respiration, required a ventilator to breathe, and was nutritionally maintained through feeding tubes. She continued to grow, her periods started, and her condition was relatively stable except for a few intercurrent hospitalizations. (7-9)

In September 2014, the author, Dr. Calixto Machado, a Cuban neurologist, was invited to travel to New Jersey as an expert advisor. Jahi was studied at the Rutgers Hospital. Dr. Charles Prestigiacomo, a us licensed neurologist, examined her and prescribed the ancillary tests suggested by Dr. Machado. EEgs were also recorded at the apartment where Jahi stayed in New Jersey. These studies have recently been published in the Journal of Functional Neurology, Ergonomics, and Rehabilitation (FNRE). (13) The author of this paper did not have access to Jahi McMath's initial medical record when diagnosed in California.

In 2018, the patient developed liver failure and underwent exploratory abdominal surgery for inexplicable bleeding. When surgeons proposed more operations, her mother sadly expressed, "Let her go," On June 22, 2018, Jahi died in the hospital, surrounded by her family. Oddly enough, she had two death certificates; the California certificate indicating that she died on December 13, 2013, and the New Jersey certificate affirming that she had died on June 22, 2018, with liver failure and hypoxic brain injury as the causes of death. (7-10)

Summarizing my findings in Jahi McMath after nine months of her initial diagnosis $(6,13)$

1) Clinical examination. The patient was supine on a bed, with her eyes closed, and demonstrated no signs of self-awareness or awareness of the environment. Neurological examination revealed a complete loss of brainstem reflexes (corneal, oculocephalic, oculovestibular, gag, and cough). The patient could not trigger 
a ventilator, and the patient's relatives did not permit an additional apnea test beyond the originally performed nine months prior. Her Coma Recovery Scale-Revised (CRS-R) total score was 3 (reproducible movement upon command).

2) Her magnetic resonance imaging (MRI) showed preservation of intracranial structures but enormous abnormalities documented nine months after cardiac arrest: remarkable preservation of cortical and brainstem gross anatomy with unexpected relative slight atrophy despite cortical laminar necrosis, demyelination, and cystic encephalomalacia in the centrum semiovale, corpus callosum, and posterior pons and medulla. MRI in Jahi also showed a massive lesion in the posterior regions of the pons, lateralized to the left.

3) EEG bioelectrical activity was over $2 \mu \mathrm{V}$ of amplitude. Moreover, the power spectral analysis proved generalized predominant activity within the delta-theta range.

4) All heart rate variability (HRV) bands were preserved in this patient.

5) Autonomic reactivity, assessed by HRV, to "Mother Talks" stimulation demonstrated preservation of function at different levels of the autonomic system.

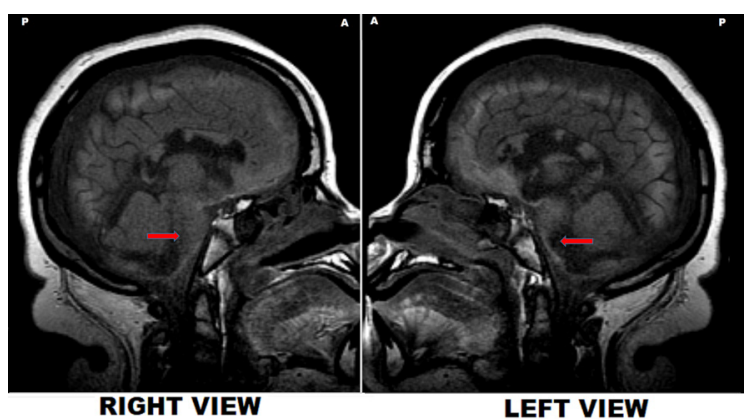

Figure 1. Jahi McMath's MRI - T1 sagittal right vs. left views. Note. Her MRI showed preservation of intracranial structures but vast abnormalities, documented nine months after a cardiac arrest: remarkable preservation of cortical and brainstem gross anatomy with unexpected relative slight atrophy despite cortical laminar necrosis, demyelination, and cystic encephalomalacia in the centrum semiovale, corpus callosum, and posterior pons and medulla. It also showed a massive lesion in the posterior regions of the pons, lateralized to the left(arrows). Source: own elaboration

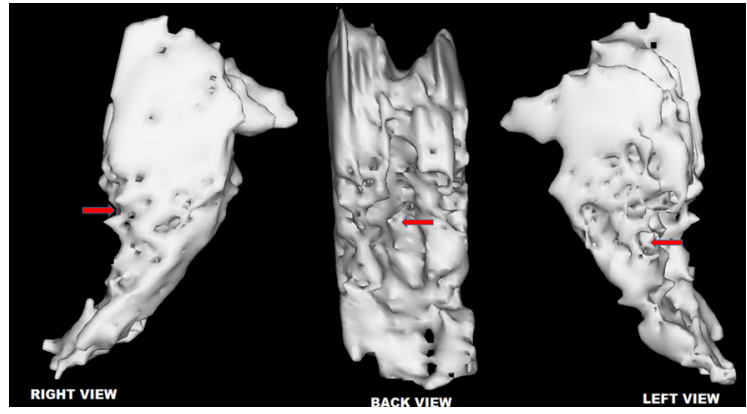

Figure 2. mri - 3D reconstruction of right, central and left views. Note. The left arrows show a huge lesion at the pons, lateralized to the left side in its posterior region. The lateral regions of the pons and mesencephalon are relatively spared.

Source: own elaboration

\section{Pathophysiological Explanation of Jahi Mcmath's Findings}

The patient showed clinical features of the $\mathrm{BD}$ state, such as the absence of brainstem reflexes and no spontaneous drive to breathe (apnea), requiring permanent mechanical ventilation. Nonetheless, preservation of intracranial structures, remaining brain function in both brainstem and cerebral hemispheres, and autonomic reactivity response to the "Mother Talks" stimulus was demonstrated in this case. $(6,13,14)$

\section{Preservation of intracranial structures}

A striking finding was the preservation of intracranial structures both in the brainstem and cerebral hemispheres, which was observed nine months after cardiac arrest resulting in severe brain injury. (13) It has been extensively described that a brain-dead patient lacks cerebral blood flow (CBF). $(15,16)$

The fact that the patient had preserved intracranial structures indicates that her cerebral perfusion was not absent. Bernat recently emphasized that "the most confident way to demonstrate that the global loss of clinical brain functions is irreversible is to show the complete absence of intracranial blood flow." (17, p163) Neurons are irreversibly damaged after a few minutes of complete cessation of $\mathrm{CBF}$ and globally destroyed when blood flow 
completely stops in about 20-30 minutes at normal body temperature. Hence, if $\mathrm{CBF}$ has stopped for more than 30 minutes, this proves brain damage irreversibility in $\mathrm{BD}$. The rationale is that the absence of cerebral circulation for this period causes total brain infarct. $(6,18-20)$

Neuropathologists coined the term "respirator brain" to describe the pathological findings in supported brain-dead patients, characterized by a dusky-congested brain containing liquid portions, frequently with brain fragmentation when removed from the calvarium. Neuronal damage is mostly extensive and proportionate to the clinical findings. The respirator brain phenomenon results from the arrest of intra-cerebral perfusion, and the time on the ventilator correlates with the extent of brain damage. $(21,22)$

Wijdicks recently studied a series of brain-dead patients and documented that no distinguishing neuropathological BD features were found, probably because timing to brain fixation has been reduced as a consequence of timely organ transplant protocols. (21) This was not the case in Jahi McMath because an MRI study was performed nine months after the initial insult. (13)

Therefore, the first argument against the diagnosis of $\mathrm{BD}$, nine months after the initial diagnosis is the preservation of intracranial structures. Shewmon has reported a series of brain-dead patients with extended somatic survival. (23-25) He expressly referred to Repertinger et al.'s case of a 4-year-old child diagnosed as brain-dead after bacterial meningitis and was then put on a ventilator for 19 years. The autopsy revealed a $750 \mathrm{~g}$ calcified intracranial spherical structure and a calcified shell containing grumous material and cystic spaces with no recognizable neural elements grossly or microscopically. (26) Nothing similar was found in this patient's MRI sequences, despite a vast brain insult. Hence, this fact contradicts $\mathrm{BD}$ diagnosis in this patient. $(13,14,27)$

\section{Preservation of EEG activity}

EEG bioelectrical activity was found over $2 \mu \mathrm{V}$ of amplitude in this case. The power spectral analysis showed a predominant activity within the delta-theta range., which demonstrates that this patient did not show a pattern of "electrocerebral inactivity" (ECI). ${ }^{13}$

The clinical diagnosis of $\mathrm{BD}$ is established after excluding potential confounders (e.g., hypothermia, endocrine or metabolic causes, intoxication, sedation, relaxation, neuromuscular disorders), demonstrating an irreversible coma with complete absence of brainstem reflexes and apnea testing. (20) The American Academy of Neurology (AAN) Guidelines affirmed that BD is based on a clinical diagnosis; however, the same guidelines recognize that in some circumstances, specific components of the clinical examination cannot be reliably tested or evaluated, suggesting the use of a confirmatory test. (28-30) In a recent article exploring the variability of $\mathrm{BD}$ policies in the United States concerning the AAN Guidelines, EEG was listed in $78.8 \%$ of policies and was the most frequent confirmatory test in BD diagnosis. (28)

Hence, it is widely accepted that $\mathrm{BD}$ is based on a clinical diagnosis, and several guidelines affirm that confirmatory tests are not mandatory. (28-30) Nonetheless, in several geographic zones, including continental Europe, Central and South Ameri$\mathrm{ca}$, and Asia, an EEG showing ECI is required by law for the certification of BD. (4)

One of the main reasons for the use of EEG and other ancillary tests is related to the accepted definition of death on neurological grounds. $(2,14,16)$ In the last decades, three main brain-oriented formulations of death have been discussed: whole-brain, brainstem death, and higher-brain standards. (20,31-33)

James Bernat claimed that "the formulation of whole-brain death provides the most congruent map for our correct understanding of the concept of death." (32) This author argued that "the irreversible cessation of the clinical functions of the brain represents death because the brain is responsible for the functioning of the organism as a whole."(34) Bernat and his colleagues' view about the defense of the whole-brain formulation of death was cited by the United States President's Commission for the Study of Ethical Problems in Medicine and Biomedical and Behavioral Research as the conceptual basis of BD. $(1,32)$ President's Commission 
recommended the adoption by all us states of the Uniform Determination of Death Act (UDDA). (35)

Christopher Pallis articulated the brainstem death view, which dismissed the use of EEG or CBF studies as confirmatory tests in BD diagnosis. (36) Wijdicks, senior author of the AAN Guidelines on $\mathrm{BD}$, has emphasized that "the irreversible absence of functions of the brainstem is the necessary and sufficient component of brain death, and this can be assessed and diagnosed clinically at the bedside" (37), which is entirely in concordance with the brainstem and not the whole-brain view of $\mathrm{BD}$. $(16,20,27,38)$

Jahi McMath was diagnosed and studied in the Us, and therefore $\mathrm{BD}$ diagnosis was considered under the whole-brain criterion. (13) The wholebrain criterion refers to the irreversible cessation of intracranial structure functions, both of the brainstem and cerebral hemispheres, (32); therefore, most defenders of this view suggest EEG as a powerful diagnostic tool. $(4,20)$

Another clinical condition where there is controversy about using EEG in BD is when intracranial pathology is localized in the posterior fossa. Both intracranial blood flow and EEG may persist when a primary brainstem catastrophe does not produce markedly raised intracranial pressure. In the presence of a primary supratentorial brain lesion, a severe forebrain lesion is combined with the subsequent gradual loss of brainstem function due to rostrocaudal transtentorial brain herniation. In the case of a secondary brain lesion (e.g., cerebral hypoxia), the brainstem is also affected like the forebrain. However, a minority of patients who have a primary infratentorial brain lesion (e.g., basilar artery thrombosis or large brainstem or cerebellar bleed) may retain blood flow and even EEG activity. (4,16,20,27,39-42)

Grigg and colleagues performed a single-center study of 56 patients declared brain-dead by clinical criteria and reported that $20 \%$ had persistent EEG activity, suggesting that EEG is not necessary to confirm BD. However, more than a third of the patients did not undergo apnea testing, and $\mathrm{PCO}_{2}$ thresholds for declaring BD were not described in the remaining cases. Moreover, pathologic studies performed in only two cases demonstrated ischemic necrosis of the brainstem with relative preservation of the cerebral cortex. The pathologic examination of the remaining cases was not described. (43)

Ferbert reported a case with a hematoma on the cerebellum and the pons, showing preserved EEG and visual evoked potentials (VEP), whereas all brainstem clinical signs of $\mathrm{BD}$ were present, concluding that in infratentorial lesions, EEG should be mandatory to confirm BD. (41)

Varela et al. analyzed three cases out of 161 who met inclusion criteria, adding a patient from another hospital. (39) All four patients suffered from catastrophic posterior fossa injuries, fulfilling the United Kingdom (uk) brainstem death clinical criteria, including the apnea test. Those four patients showed preservation of supratentorial blood flow, which disappeared after a period of 2 to 6 days, allowing then $\mathrm{BD}$ declaration according to the whole-brain criteria.

Nonetheless, the challenge of the cases above fwas to determine when the patients were braindead according to Us or UK BD criteria. According to UK guidelines, patients were brain-dead after the first clinical evaluation, but after six days, all four patients were brain-dead according to us guidelines. Jahi McMath had preserved CBF up to nine months. $(6,13)$ This conceptual and practical difference in $\mathrm{BD}$ determination between the us and the UK in patients with a primary brainstem lesion remains controversial and has been known as the "transatlantic divide". $(42,44)$

Wijdicks commented that in one study of patients fulfilling clinical BD criteria, $20 \%$ of 56 patients had residual EEG activity that lasted up to 168 hours. This author also noted that the sensitivity and specificity of EEG in BD diagnosis are $90 \%$. (37) Nonetheless, this author emphasized there were no reports of patients who fulfilled clinical brainstem death criteria and survived, (44) but this statement is related to prognosis and not to diagnosis. (27)

According to us- BD criteria, Varela et al. concluded that patients with primary posterior fossa catastrophic lesions who clinically seemed to be brain-dead would typically evolve from retaining to losing supratentorial blood flow. Therefore, the 
authors affirmed that if CBF assessment is used as an ancillary test, those patients are like those who become BD due to supratentorial lesions. They also commented on the theoretical possibility of lesions sparing the mesopontine tegmental reticular formation due to isolated brainstem injury, leading to a total apneic locked-in syndrome (LIS), imitating brainstem death. (39) They affirmed that this condition does not rule out the possibility that a patient with a primary infratentorial might still be conscious to some degree for some time. (45)

Varela et al. also emphasized that there are no reports of brain-dead patients correctly diagnosed under either the whole-brain or brainstem views, who have shown regained consciousness or breathing recommence. Then, they erroneously stated that persistent supratentorial CBF or EEG activity does not indicate remaining brain function, ${ }^{39}$ which was not the case in Jahi McMath. $(13,14)$

Moreover, experimental studies in animals have found that near-normal EEG involving predominant alpha, beta, or theta activity is not likely to occur in substantive neuronal damage to the mesopontine tegmental reticular formation . Therefore, these authors remarked that ancillary tests are mandatory for diagnosing BD to find either electro-cortical inactivity or, preferably, cerebral circulatory arrest. Consequently, in such patients, the presence of an irreversible coma must be disbelieved, and the possibility that some degree of consciousness remains cannot be excluded if there is EEG activity. (4,45-47)

These reports of cases with infratentorial brain lesions showing a near-normal electroencephalogram (EEG) combined with well-preserved cortical VEPs after the diagnosis of $\mathrm{BD}$ led to stricter $\mathrm{BD}$ codes in several countries. These stricter BD codes include the obligatory demonstration of electro-cortical silence (on EEG) or cerebral circulatory arrest (on cerebral angiography, perfusion scintigraphy, or Doppler sonography) in patients with a primary infratentorial lesion. $(4,43,45)$

In summary, EEG has a long history as a confirmatory test in BD. In this case, EEG demonstrated the preservation of brain function at the level of the cerebral cortex. $(6,16)$

\section{Preservation of central nervous autonomic system function}

HRV It was possible to reveal the preservation of all HRV bands in this patient using the HRV methodology. The high frequency (HF) component is considered a marker of the parasympathetic cholinergic central system, with responses mainly in the nucleus ambiguous. The low frequency (LF) band is related to vagal and sympathetic influences. The middle frequency $(\mathrm{MF})$ band has been correlated to the biofeedback of the baroreceptor function and Meyer blood pressure waves. Meanwhile, the very low frequency (VLF) range has been associated with the pressor arm of the sympathetic adrenergic system, central thermoregulatory centers, and the renin-angiotensin system. (48-51)

HRV The loss of all HRV power has characterized BD. ${ }^{51-53}$ My group and I recently reported a braindead case in which the VLF oscillations were the last to vanish. It was possibly related to the residual sympathetic vasomotor activity that progressively disappeared due to the extension of necrosis affecting the nervous centers of the lower part of the medulla and the first 2-3 cervical spine segments. Therefore, the preservation of HRV bands in this patient demonstrated persistent medullary autonomic activity within the vagal and other autonomic central nuclei. $(6,13,49)$

Another key finding, in this case, was the autonomic reactivity to "Mother Talks" stimulation compared to other women's aged-matched voices. We validated this stimulus ("Mother Talks") in unresponsive wakefulness syndrome (Uws) patients. $(38,54)$. We also reported the effect of Zolpidem in uws patients and could demonstrate an autonomic reactivity to this drug. (55) Several authors have reported brain activation in response to a familiar voice saying the patient's name using fuctional MRI (fMRI) and event-related potentials. $(56,57)$ Hence, these findings in Jahi McMath proved remaining function at different levels of the central autonomic system and suggested recognition of the mother's voice based on residual linguistic processing.

Dr. Shewmon reported the analysis of videos provided by Jahi's mother. This author analyzed the complete data set, containing 189 commands to 
move various body parts and around 100 non-myoclonic movements. Dr. Shewmon described that each body part with enough non-myoclonic movements showed an approximately exponential distribution of inter-movement intervals. Thus, he concluded: "Suffice it to say that I am convinced that the apparent responses to command cannot all be explained away as mere chance occurrences of spontaneous spinal movements, facilitating statistical comparison of movement frequency during command versus baseline conditions."(8)

Therefore, our findings on autonomic reactivity to "Mother Talks" stimulus, $(38,55)$ might explain the video findings reported by Dr. Shewmon, who observed Jahi's movements and interpreted them as volitional responses to commands, and be consistent with cognitive awareness. (8)

\section{Jahi Mcmath: A New State of Consciousness. Comparison with Other Disorders of Consciousness (DOCS)}

Consciousness has two dimensions: arousal (i.e., wakefulness or vigilance) and awareness or content of consciousness (i.e., encompassing all subjective perceptions, feelings, and thoughts). It is accepted that consciousness is clinically defined as having two components: awareness and arousal. Arousal, also called wakefulness, refers to the level of alertness (clinically determined by eye opening). In contrast, awareness refers to the content of consciousness (clinically determined by command following or non-reflex motor behavior such as eye-tracking or localized responses to pain). $(16,20,42,58-60)$

The most discernible change that occurs when waking is eye opening. $(16,33,58,61,62)$ Arousal is also known as the capacity for consciousness. $(16,63)$ Arousal is anatomically related to structures in the brain and specifically the brainstem and hypothalamus. Meanwhile, awareness is related to a vast frontoparietal network encompassing associative cortices and, more specifically, the intrinsic connectivity of this network and the connectivity between the frontoparietal associative cortices and the thalamus. Hence, arousal seems to be indispensable for awareness to emerge. It is necessary to be awake in order to be aware. Arousal represents a group of behavioral changes that occurs when a person awakens from sleep or coma and transits to a state of alertness. Changes in arousal, mediated by an interaction between the ascending arousal system and the neocortex, may strongly modulate neuronal activity in much of the brain. (64) Tracking brain arousal fluctuations with fMRI changes in cortical arousal are mediated by ascending pathways projecting from the brainstem through the cingulate fiber bundle and the thalamus. (65) Modulation of arousal gives rise to changes in behavior and responsiveness to sensory stimuli. (66) The neurophysiological correlates of changes in the arousal state can be observed non-invasively by EEG and more recently have been shown to have correlates in human fMRI resembling the pattern linked with the spontaneous eye behavior observed here. (64)

According to the Multi-Society Task Force for Permanent Vegetative State (67) and the Royal College of Physicians, (68), "wakefulness" refers to the presence of typically cycling periods of eye-closure and eye-opening that give the appearance of sleepwake cycles.

Awareness, also known as the content of consciousness, represents the sum of cognitive and affective mental functions and denotes the knowledge of one's existence and the recognition of internal and external worlds. $(58-60,69)$ Though, to be awake is not enough to be aware. There are, in fact, some exceptional cases in which these two components are dissociated. On the one hand, in the rapid eye movement stage of sleep, wakefulness is impaired while internal awareness is relatively spared. On the other hand, in uws), (70) the minimally conscious state (MCs), and some more transient states such as absence seizures, complex partial seizures, or somnambulism, awareness is impaired while wakefulness is spared. $(46,71)$

Therefore, awareness has been classified as: $(58,59,72)$

- external awareness (i.e., sensory or perceptual awareness of the environment)

- internal awareness (i.e., stimulus-independent 
thoughts, mental imagery, inner speech, daydreaming, or mind-wandering)

Some authors have suggested that the awareness network can be subdivided into two different networks: the intrinsic (default mode network [DMN]) and the extrinsic awareness network [executive control network (ECN)]. The extrinsic awareness network includes the lateral frontoparietal brain regions and is linked to sensory awareness or awareness of the environment. The intrinsic awareness network involves mainly the medial prefrontal cortex and the precuneus and bilateral posterior parietal cortices and is related to internal awareness or self-related processes, such as mind-wandering and autobiographical thinking. (58)

Novel neuroimaging techniques in patients with DOC provide critical insights into understanding consciousness and the differential diagnosis of clinical Doc Docentities, given that behavioral assessment alone can sometimes be incorrect and imprecise. Functional neuroimaging methods have made it possible to study cognitive processing objectively in the absence of behavioral reports. Positron emission tomography (PET) measures different aspects of metabolic function according to the type of administered radioactive tracer. Structural conventional MRI and diffusion tensor imaging (DTI) reveal the structural properties of the brain and the white matter integrity, respectively. fMRI quantifies brain function derived from blood-oxygen-level-dependent (BOLD) changes. TMS/EEG allows stimulating a subset of cortical neurons non-invasively and measure the effects of this perturbation on the rest of the brain. This knowledge has given rise to the search for other non-clinical assessment techniques that can better understand brain function in these patients and overcome the limits of behavioral assessment in detecting possible retained consciousness in unresponsive patients. (64)

Therefore, by combining behavior to functional brain imaging, we may not only correct some diagnosis errors but also eventually discover some behavioral complements to unconscious cortically driven patterns of activity in uws patients. Chang proposed a new terminology of Docs joining clinical and functional brain imaging evidence and suggested replacing the term MCs by cortically mediated state (CMS) and dividing the four major clinical states (comatose, Uws, CMS, and conscious states) into eight categories, according to the source of evidence used to define them . As an interim conclusion, the CRS-R enables us to differentiate behaviors relying on cortical activity from those that do not. This clinical tool, therefore, constitutes a powerful probe of CMS. From this perspectiveand in the strictest sense-, the CRS-R enables us to recognize CMs rather than MCs. (64)

The classification of Docs is based on clinical findings plus neuroimaging techniques, such as quantitative EEG, quantitative high-density EEG, fMrI, and PET. Nonetheless, these methods are not widely available and may be logistically complicated in mechanically ventilated patients. (64)

There is no conclusive way to clinically assess "internal awareness" in a patient otherwise incapable of expressing awareness in response to external environmental stimuli. Internal awareness is a subjective dimension of consciousness. Consequently, it is supposedly impossible to exclude that some Docs are indeed conscious. Assessing the preservation or absence of one or both consciousness components is crucial for classifying Docs. $(16,73)$

Coma is a sleep-like state of unarousability and unresponsiveness without evidence of self-awareness or awareness of the environment, occurring after severe brain injury. Patients surviving severe brain damage may end up in a coma. This state may arise following structural or metabolic lesions to the brainstem reticular system or due to widespread bilateral cerebral damage. Patients in a coma show a continuous absence of eye opening and spontaneous or stimulus-induced arousal or voluntary behavioral responses. Hence, they are neither awake nor aware. (46)

Nonetheless, coma is a time-limited condition (it usually does not last longer than a few weeks) leading either to $\mathrm{BD}$ (i.e., permanent loss of brainstem functions), a uws, or regained consciousness. If the patients survive their brain lesions, they will first be plunged into a period of coma where they will be unarousable and unconscious. This period is transient, and after some days or weeks, the patients may evolve to $\mathrm{BD}$, losing all brainstem functions permanently, i.e., no brainstem reflexes. $(58,74,75)$ 
Jahi was diagnosed with BD because her clinical examination demonstrated a sleep-like state of unarousability and unresponsiveness without evidence of self-awareness or awareness of the environment, no brainstem reflexes, no spontaneous respiratory drive (apnea), and that she required permanent mechanical ventilation. Nonetheless, ancillary tests, performed nine months after initial brain insult, showed conservation of intracranial structures, EEG activity, and autonomic reactivity to "Mother Talks" stimulus, demonstrating preserved function in both the brainstem and the cerebral hemispheres. All these findings speak against a diagnosis of $\mathrm{BD} .(6,13)$

She was not comatose because although she was clinically in a sleep-like state of unarousability and unresponsiveness without evidence of self-awareness or awareness of the environment, $(46,58,74)$ the complete absence of brainstem reflexes dismissed this possibility. $(6,13)$ Repetitive clinical assessment excluded the presence of confounding factors (e.g., drug intoxication, hypothermia) that would have explained the absence of brainstem reflexes in suspected BD. ${ }^{13}$

As discussed, some comatose patients show a favorable outcome, recovering arousal signs, i.e., they open their eyes spontaneously or on stimulation, but remain un-self-aware or unaware of the environment (showig only reflex motor response). (70) This condition was firstly named vegetative state (vs) in 1972. (76) More recently, vs, which can be erroneously considered as "vegetable"-like, has been recognized using a more descriptive and unbiased term: unresponsive wakefulness syndrome (uws). $(38,70,77)$ Therefore, Jahi McMath had no uws because she was not in a wakefulness state and showed partial responsiveness. Moreover, uws patients preserve fully or partially brainstem reflexes and usually breathe independently without mechanical ventilation. $(6,13)$

Another condition, LIS, $(45,72)$ characterized by a highly restricted ability to demonstrate motor responses indicating awareness due to dysfunction of the corticospinal tracts, is frequently wrongly included as a DOC. $(6,42,78,79)$ LIs traditionally refers to patients who are totally paralyzed (ophthalmoplegia, anarthria, tetraplegia) but fully conscious and able to use vertical eye movements or blink to communicate. Therefore, LIS is not a Doc but can be (and often is) mistaken for one. Moreover, patients with LIs due to acute brainstem lesions may first be in a coma and progressively wake up throughout the following days but remain paralyzed and voiceless, resembling patients with uws. It has been affirmed by several authors that patients with LIS do not inevitably rate their quality of life as meaningless. The pupillary reflex is regularly preserved in LIS and might be the only remaining brainstem reflex. (80) There are, however, single case reports of LIS with dilated pupils. Therefore, clinicians must be aware of possible pitfalls in LIs diagnosis. (72)

Jahi had not LIs because she was not in a wakefulness state and only showed partial responsiveness. $(6,42,78)$ Moreover, LIs patients, although quadriplegic, usually preserve fully or partially brainstem reflexes, vertical eye movements, or blinking, and most patients respire on their own, not requiring mechanical ventilation. (72)LIs patients may also be apneic with permanent or transient failure to trigger the ventilator. (81) Wijdicks has remarked that "I am particularly baffled when it is suggested that patients with no brainstem function might be locked in with functioning thinking parts of the brain." (82) Nonetheless, Jahi theoretically, was in the most severe, imaginable, locked-in state. $(6,42,78)$

The uws can either not progress anymore or evolve to a state in which patients show inconsistent but reproducible, limited but discernible, evidence of self-awareness or awareness of the environment. $(6,42,70,78,83,84)$ In 2002, the Aspen Neurobehavioral Conference Workgroup referred to this condition as the "minimally conscious state" (MCS). (83)

Jahi was not an MCs patient, but this requires a more detailed discussion. MCs is a condition of severely altered consciousness characterized by minimal, inconstant yet definite behavioral signs of self-awareness and awareness of the surroundings. Based on the level of their purposeful behavioral signs, MCs patients were recently subcategorized as MCs plus (command following, intelligible 
verbalizations, or non-functional communication) and MCs minus (visual pursuit, localization of noxious stimulation, or contingent behavior such as appropriate smiling or crying to emotional stimuli). Patients may emerge from MCs once they regain the ability to communicate reliably or use objects functionally. $(46,85)$

The Aspen Workgroup stated that MCs shows both components of consciousness and proposed the following:(83,84)

Regarding arousal:

- eyes open spontaneously;

- normal to abnormal sleep-wake cycle;

- arousal level ranges from obtunded to normal.

Regarding awareness:

- reproducible but inconsistent evidence of perception;

- communication ability;

- purpose-full motor activity;

- visual tracking often intact.

The Workgroup emphasized that in Mcs, sleepwake cycles ranged from normal to abnormal. (83) In fact, this was reported by Cruse et al., who have shown, using an indirect measure of sleep-wake rhythmicity (wrist actigraphy), that a substantial amount of UWs and MCS patients do not reveal statistically consistent circadian sleep-wake rhythms. However, sleep-wake cycles of MCs patients were more statistically reliable than UWS cases. Nonetheless, an important warning is that the ostensible nonappearance of consistent circadian rhythms in some of their patients may result from a lack of sensitivity of the actigraphy method rather than from the actual absence of those rhythms. (86)

Moreover, Welek et al. studied day-night variations of EEG activity and sleep, recorded over 24 hours at the bedside, and observed higher signal complexity during light-on periods than nighttime only in controls MCS patients. Furthermore, these day-night changes of brain dynamics appeared to steadily rise from Uws to MCs in control participants, which reflect their cognitive capabilities or degree of conscious awareness. (87)
Hence, Jahi was not an MCs. MCs From the neurobehavioral point of view, a key difference is that she did not preserve arousal as mCs patients do because she was in a sleep-like condition, resembling either a coma or a BD state. It was not determined if she maintained some remaining sleep-wake cycles using neurophysiological techniques. $(6,42,88)$ She showed partial awareness, indirectly assessed by videos, according to Dr. Shewmon, (7-9) and by my autonomic findings from Mother Talks stimulus. $(13,42)$ It is possible to state that she demonstrated reproducible but inconsistent evidence of perception, communication ability, and purpose-full motor activity. Of course, she did not show visual tracking. (13)

Furthermore, MCs patients preserve fully or partially brainstem reflexes and regularly breathe on their own, without mechanical ventilation. Wannez et al. has emphasized that the CRS-R is the most sensitive scale to differentiate the different Docs, and eleven items of the scale allow detecting the MCs. (89) The CRS-R comprises 23 items distributed in six subscales assessing different functions, i.e., auditory, visual, motor, and oromotor/ verbal functions, communication, and arousal. According to Giacino et al., the CRS-R is capable of distinguishing Uws from MCs. (90) If the examiner assesses only five items, movement to command, visual pursuit, fixation, localization to noxious stimulation, and automatic motor response, almost $99 \%$ of patients will be correctly diagnosed as MCs. (89) The application of the CRS-R to Jahi resulted in a very low value (i.e., 3 ), not corresponding with MCs patients' usual CRS-R scores. $(6,13,14,42)$

Another crucial difference is that MCs has always been described as a transitional state between coma, Uws, and a higher level of consciousness. Moreover, clinical findings well-matched with MCs may occur at onset, without an identifiable period of coma or uws. Some patients may endure an MCS as a chronic condition. $(42,71,78,84)$ But an MCs has never been reported in a patient with all clinical BD findings: absent brainstem reflexes and apnea. $(6,13,14,42)$ Furthermore, Jahi was not in a CMS, regarding the new classification recently proposed by Naccache. ${ }^{91}$ 


\section{Pathophysiological Explanation of Partial Awareness Preservation in Jahi McMath}

Pavizi and Damasio reported a case series including 47 patients with isolated brainstem lesions, of whom nine were in a coma. (69) These authors affirmed that long-duration coma is often correlated with bilateral lesions of either the upper pontine tegmentum or the upper pontine and mesencephalic tegmentums. The lesions of the upper pontine tegmentum involved the raphe complex, locus coeruleus and subcoeruleus (LC), laterodorsal tegmental nucleus (LDT), pedunculopontine tegmental nucleus (PPT), pontis oralis nucleus (PO), and lateral and medial parabrachial nuclei (LPB, MPB). The local connections between these nuclei and the ascending central tegmental tract were also disengaged. These authors remarked that the maximum lesion overlay area in patients with coma matched the location of the PO, LC, raphe, LDT, and LPB/MPB nuclei. Interestingly, most of the reported patients later regained consciousness. The findings of a recent voxel-based lesion-symptom mapping study confirmed the obligatory involvement of rostral dorsolateral pontine tegmentum in brainstem coma. (92)

Several authors have affirmed that preserving some structures is mandatory to establish some degree of consciousness in humans: critical parts of the mesopontine reticular formation, its dorsal pathway to the thalamocortical or its ventral pathway to the cortico-cortical projection systems, and parts of the associative cerebral cortices. $(4,45,58)$

Snider et al. Mriassessed the ascending arousal network (AAn) using MRI high-angular-resolution diffusion technology in patients in a coma with a traumatic injury. These authors used the probabilistic tractography method to measure the connectivity probability (CP) of AAn axonal pathways linking the brainstem tegmentum to the hypothalamus, thalamus, and basal forebrain. Compared to controls, patients showed a reduction in AAn pathways connecting the brainstem tegmentum to a region of interest encircling the hypothalamus, thalamus, and basal forebrain. When each pathway was examined individually, brainstem-hypothalamus and brainstem-thalamus $\mathrm{CP}$, but not brainstem-forebrain $\mathrm{CP}$, were significantly reduced in patients. Hence, these authors emphasized that the relative conservation of brainstem-forebrain CP in comatose patients is unexpected, given confirmation from animal studies that brainstem-forebrain connectivity contributes to consciousness. They concluded that brainstem disconnection from the basal forebrain might not be essential to produce coma, but conserved brainstem-forebrain connectivity is still a requisite for regaining consciousness. (93)

Resting-state fMrI studies have shown that the midline frontoparietal "default mode" connectivity reflects internal awareness (i.e., spontaneous thoughts, inner speech, and mind-wandering that disappears in BD and decreases in Uws). (94) Nonetheless, consciousness does not maintain a simple one to one relationship with higher or lower brain structures. $(5,16,61)$

Varela et al. opined that there is a small minority of patients who have a massive primary injury to the brainstem (e.g., from basilar artery thrombosis), and even though they are in a deep coma, have preserved $\mathrm{CBF}$ and EEG, which may be questionable indicators of remaining consciousness in isolated cases. These authors have also questioned whether patients with this type of brainstem injury might recover function or consciousness at some level. (39)

In 1994, in a theoretical paper about the definition of death, on neurological grounds, the author of this paper proposed:(33)

"In cases fulfilling the 'brainstem criteria of BD,' with primary brainstem lesions, and preserved cerebral hemispheres, stimulation of non-specific thalamic nuclei, might produce some degree of arousal."

Walter et al. have suggested that from the anatomic point of view, the "brainstem-death" syndrome can hypothetically happen without relevant lesion of the mesopontine tegmental reticular formation. $(4,45)$

Although a detailed review of the contribution of neuronal input from the brainstem to the function of the cerebral hemispheres is outside the scope of this article, it has been extensively investigated in animal models by Bremer in 1935 (the 
cerveau isolé), (95) Lindsley et al. in 1949 (the encephale isolé), (96) and other authors. (97)

As previously noted, Jahi McMath's MRI demonstrated a large lesion in the pons. Hence, several reasons might explain the intermittent conscious responses in this patient, including the relative intactness of the upper brainstem, thalamus, and cortex and the partial sparing of the mesopontine tegmental reticular formation. She might also have preserved its connections to the thalamocortical or its ventral pathway to the cortico-cortical projection systems, and parts of the associative cerebral cortices. $(6,13,42)$ Therefore, Walter et al. were not far from the truth when they hypothesized that "a brainstem lesion may cause an apneic total locked-in syndrome, a rare syndrome with preserved capability for consciousness, mimicking brainstem death." $(4,45)$

\section{CONCLUSION}

In this paper, I reviewed the case of Jahi McMath, who was diagnosed with BD. I have comprehensively discussed that she did not have BD UwS or LIS or was in a coma, MCs or CMS, regarding the recent classification of Docs proposed by Naccache. She was closer to the diagnosis of Lis but did not fulfill the diagnostic criteria for this state. She could be described as having unawake LIs. $(6,13,42)$

Jahi McMath was an unusual and quarrelsome case. It does not deny the concept of $\mathrm{BD}$ but brings again the needs of using ancillary tests in BD confirmation up for discussion. $(6,13,14,16,42,98)$

I concluded that Jahi had a new Doc, non-previously described, that I have termed: "reponsive unawakefulness syndrome" (RUS).

\section{REFERENCES}

1. Bernat JL, Brust JCM. Strategies to improve uniformity in brain death determination. Neurology. 2019;92:401402. DOI: $10.1212 /$ wnl.0000000000006994

2. Machado C, Estevez M, DeFina PA, Leisman G. Reader response: An interdisciplinary response to contemporary concerns about brain death determination. Neurology. 2018;91(11):535. DoI: 10.1212/01. wnl.0000544244.66565.8d
3. Machado C, Perez J, Scherle C, Areu A, Pando A. Brain death diagnosis and apnea test safety. Ann Indian Acad Neurol. 2009;12(3):197-200. DoI: 10.4103/09722327.56326

4. Walter U, Brandt SA. Diagnosis of irreversible loss of brain function ("brain death")-what is new?. Nervenarzt. 2019;90:1021-1030.

5. Lewis A. Reconciling the Case of Jahi McMath. Neurocrit Care. 2018;29(1):20-22. DoI: 10.1007/s12028-0180561-5

6. Machado C, Estevez M, DeFina PA, Leisman G. Response to Lewis A: Reconciling the Case of Jahi McMath. Neurocrit Care. 2018;29(3):521-522. DOI: 10.1007/s12028-018-0602-0

7. Shewmon DA. The Case of Jahi McMath: A Neurologist's View. Hastings Cent Rep. 2018;48 Suppl 4:S74-S76. DOI: 10.1002/hast.962

8. Shewmon DA. Truly Reconciling the Case of Jahi McMath. Neurocrit Care. 2018;29(2):165-170. DOI: 10.1007/s12028-018-0593-X

9. Truog RD. Lessons from the Case of Jahi McMath. Hastings Cent Rep. 2018;48 Suppl 4:S70-S73. DOI: 10.1002/hast.961

10. Truog RD. Defining Death-Making Sense of the Case of Jahi McMath. JAMA 2018;319(18):1859-1860. DOI: 10.1001/jama.2018.3441

11. Lewis A. Response to Machado et al. re: Jahi McMath. Neurocrit Care. 2018;29(3):523-524. DOI: 10.1007/ s12028-018-0603-Z

12. Lewis A. The Legacy of Jahi McMath. Neurocrit Care. 2018;29(3):519-520. DOI: 10.1007/s12028-018-0589-6

13. Machado CD, Estevez M, Leisman G, Rodriguez R, Presitigiacomo C, Fellus J, et al. A Reason for care in the clinical evaluation of function on the spectrum of consciousness J Funct Neurol Rehabil Ergon. 2017;4:542-556.

14. Machado C, Estevez M. Reader Response: Practice Current: When do you order ancillary tests to determine brain death? Neurol Clin Pract. 2018;8(5):364. DOI: 10.1212/cpj.0000000000000537

15. Heran MK, Heran NS, Shemie SD. A review of ancillary tests in evaluating brain death. Can J Neurol Sci. 2008;35:409-419.

16. Machado C. Brain Death: A reappraisal. New York: Springer Science+Bussiness Media, LLC; 2007.

17. Bernat JL. On irreversibility as a prerequisite for brain death determination. Adv Exp Med Biol. 2004;550:161167. DOI: $10.1007 / 978-0-306-48526-8 \_14$ 
18. Ingvar $\mathrm{DH}$. Brain death--total brain infarction. Acta Anaesthesiol Scand Suppl. 1971;45:129-140. DoI: 10.1111/j.1399-6576.1971.tb00668.x

19. Machado C. Are brain death findings reversible? Pediatr Neurol. 2010;42(4):305-306. DOI: 10.1016/j.pediatrneurol.2009.11.013

20. Machado C. Diagnosis of brain death. Neurol Int. 2010;2:e2.

21. Wijdicks EF, Pfeifer EA. Neuropathology of brain death in the modern transplant era. Neurology. 2008;70(15):1234-1237. DOI: 10.1212/01. wnl.0000289762.50376.b6

22. Walker AE, Diamond EL, Moseley J. The neuropathological findings in irreversible coma. A critique of the “respirator." J Neuropathol Exp Neurol. 1975;34(4):295323. DoI: 10.1097/00005072-197507000-00001

23. Shewmon AD. The brain and somatic integration: insights into the standard biological rationale for equating "brain death" with death. J Med Philos. 2001;26(5):457-478. DoI: 10.1076/jmep.26.5.457.3000

24. Shewmon DA, Holmes GL, Byrne PA. Consciousness in congenitally decorticate children: developmental vegetative state as self-fulfilling prophecy. Dev Med Child Neurol. 1999;41(6):364-374. Dor: 10.1017/ s0012162299000821

25. Shewmon DA. Spinal shock and brain death': somatic pathophysiological equivalence and implications for the integrative-unity rationale. Spinal Cord. 1999;37(5):313-324. DoI: 10.1038/sj.sc.3100836

26. Repertinger S, Fitzgibbons WP, Omojola MF, Brumback RA. Long survival following bacterial meningitis-associated brain destruction. J Child Neurol. 2006;21(7):591595. DOI: $10.1177 / 08830738060210070401$

27. Machado C. Reader response: Variability in reported physician practices for brain death determination. Neurology. 2020;94(2):97. DOI: 10.1212/ wnl.0000000000008790

28. Greer DM, Wang HH, Robinson JD, Varelas PN, Henderson GV, Wijdicks EF. Variability of Brain Death Policies in the United States. JAma Neurol. 2016;73(2):213-218. Dor: 10.1001/jamaneurol.2015.3943

29. Wijdicks EF. Determining brain death in adults. Neurology. 1995;45:1003-1011.

30. Wijdicks EF, Varelas PN, Gronseth GS, Greer DM. Evidence-based guideline update: determining brain death in adults: report of the Quality Standards Subcommittee of the American Academy of Neurology. Neurology. 2010;74(23):1911-1918. DOI: 10.1212/ wnl.0b013e3181e242a 8
31. Machado C. Death as a biological notion. J Crit Care. 2014;29(6):1119-1120. DOI: 10.1016/j.jcrc.2014.07.029

32. Bernat JL. The biophilosophical basis of whole-brain death. Soc Philos Policy 2002;19(2):324-342. DoI: $10.1017 / \mathrm{s} 0265052502192132$

33. Machado C. Death on neurological grounds. J Neurosurg Sci. 1994;38:209-222.

34. BernatJL. The whole-brain concept of death remains optimum public policy. J Law Med Ethics. 2006;34(1):3543, 33. DOI: 10.1111/j.1748-720x.2006.00006.x

35. Determination of death (Uniform Determination of Death Act of 1981); natural death (Natural Death Act of 1981). LEXIS District of Columbia.

36. Pallis C. ABC of brain stem death. The arguments about the EEG. Br Med J (Clin Res Ed). 1983;286(6361):284287. DoI: $10.1136 /$ bmj.286.6361.284

37. Wijdicks EF. Determining Brain Death. Continuum (Minneap Minn). 2015;21:1411-1424. DoI: 10.1212/01. con.0000475535.64449.37

38. Machado C, Estevez M, Rodriguez R, Pérez-Nellar J, Gutiérrez J, Carballo M, et al. A Cuban perspective on management of persistent vegetative state. MEDICC Rev. 2012;14(1):44-48. DoI: 10.37757/mr2012v14.n1.3

39. Varelas PN, Brady P, Rehman M, Afshinnik A, Mehta C, Abdelhak T, et al. Primary Posterior Fossa Lesions and Preserved Supratentorial Cerebral Blood Flow: Implications for Brain Death Determination. Neurocrit Care. 2017;27(3):407-414. DoI: 10.1007/s12028-017-0442-3

40. Varelas PN. Brainstem or entire brain-based declaration of death: is there a difference? Pract Neurol. 2016;16(2):85-86. DOI: 10.1136/practneurol-2015-001348

41. Ferbert A, Buchner H, Ringelstein EB, Hacke W. Isolated brain-stem death. Case report with demonstration of preserved visual evoked potentials (vEPs). Electroencephalogr Clin Neurophysiol. 1986;65(2):157-160. DOI: 10.1016/0168-5597(86)90049-3

42. Machado C. Further thoughts about the "transatlantic divide" in brain death determination. Anaethesia. 2019;74. Available from: http://www.respond2articles. com/ANA/forums/thread/2778.asp.

43. Grigg MM, Kelly MA, Celesia GG, Ghobrial MW, Ross ER. Electroencephalographic activity after brain death. Arch Neurol. 1987;44(9):948-954. Dor: 10.1001/ archneur.1987.00520210048018

44. Wijdicks EF. The transatlantic divide over brain death determination and the debate. Brain. 2012;135(4):13211331. DOI: 10.1093/brain/awr282 
45. Walter U, Fernandez-Torre JL, Kirschstein T, Laureys $\mathrm{S}$. When is "brainstem death" brain death? The case for ancillary testing in primary infratentorial brain lesion. Clin Neurophysiol. 2018;129(11):2451-2465. DoI: 10.1016/j.clinph.2018.08.009

46. Di Perri C, Thibaut A, Heine L, Soddu A, Demertzi A, Laureys S. Measuring consciousness in coma and related states. World J Radiol. 2014;6(8):589-597. DoI: 10.4329/wjr.v6.i8.589

47. Laureys S, Schiff ND. Coma and consciousness: paradigms (re)framed by neuroimaging. Neuroimage. 2012;61(2):478-491. DOI: 10.1016/j.neuroimage.2011.12.041

48. Porges SW. The polyvagal perspective. Biol Psychol. 2007;74(2):116-143. DOI: 10.1016/j.biopsycho.2006.06.009

49. Machado C, Estevez M, Perez-Nellar J, Schiavi A. Residual vasomotor activity assessed by heart rate variability in a brain-dead case. BмJ Case Rep. 2015;2015:10.1136/bcr-2014-205677. DOI: $10.1136 /$ bcr2014-205677

50. Machado C, Korein J, Aubert E, Bosch J, Alvarez MA, Rodríguez R, et al. Recognizing a mother's voice in the persistent vegetative state. Clin EEg Neurosci. 2007;38(3):124-126. DOI: 10.1177/155005940703800306

51. Estevez-Baez M, Machado C, Garcia-Sanchez B, Rodríguez V, Alvarez-Santana R, Leisman G, et al. Autonomic impairment of patients in coma with different Glasgow coma score assessed with heart rate variability. Brain Inj. 2019;33(4):496-516. DoI: 10.1080/02699052.2018.1553312

52. Baillard C, Vivien B, Mansier P, Mangin L, Jasson S, Riou B, et al. Brain death assessment using instant spectral analysis of heart rate variability. Crit Care Med. 2002;30(2):306-310. DOI: 10.1097/00003246200202000-00007

53. Machado-Ferrer Y, Estevez M, Machado C, Hernández-Cruz A, Carrick FR, Leisman G, et al. Heart rate variability for assessing comatose patients with different Glasgow Coma Scale scores. Clin Neurophysiol. 2013;124(3):589-597. DoI: 10.1016/j.clinph.2012.09.008

54. Machado C, Estevez M, Perez-Nellar J, Gutiérrez J, Rodríguez R, Carballo M, et al. Autonomic, EEG, and behavioral arousal signs in a PVs case after Zolpidem intake. Can J Neurol Sci. 2011;38(2):341-344. DoI: $10.1017 / \mathrm{s} 0317167100011562$

55. Machado C, Estevez M, Rodriguez R, Perez-Nellar J, Chichilla M, DeFina P, et al. Zolpidem arousing effect in persistent vegetative state patients: autonomic, EEG and behavioral assessment. Curr Pharm Des. 2014;20:41854202. DOI: 10.2174/1381612811319666064656.
56. DiHB, Yu SM, Weng XC, Laureys S, Yu D, LiJQ, etal. Cerebral response to patient's own name in the vegetative and minimally conscious states. Neurology. 2007;68(12):895899. doi: 10.1212/01.wnl.0000258544.79024.d0

57. Machado C, Kerein J, Ferrer Y, Portela L, de la CGM, Manero JM. The concept of brain death did not evolve to benefit organ transplants. J Med Ethics. 2007;33(4):197-200. Dor: 10.1136/jme.2006.016931

58. Demertzi A, Tagliazucchi E, Dehaene S, Deco G, Barttfeld P, Raimondo F, et al. Human consciousness is supported by dynamic complex patterns of brain signal coordination. Sci Adv. 2019;5(2):eaat7603. DoI: 10.1126/sciadv.aat7603

59. Di Perri C, Bahri MA, Amico E, Thibaut A, Heine L, Antonopoulos G, et al. Neural correlates of consciousness in patients who have emerged from a minimally conscious state: a cross-sectional multimodal imaging study. Lancet Neurol. 2016;15(8):830-842. DoI: 10.1016/ s1474-4422(16)00111-3

60. Wijdicks EFM. The Ascending Reticular Activating System. Neurocrit Care. 2019;31:419-422.

61. Machado C, Estevez M, Redriguez R, Perez-Nellar J, Silva S, Loubinoux I, et al. Wakefulness and loss of awareness: brain and brainstem interaction in the vegetative state. Neurology. 2010;75(8):751-752. DOI: 10.1212/wnl.0b013e3181ec67bb

62. Machado C, Rodriguez R, Carballo M, Korein J, Sanchez-Catasus C, Pérez J, et al. Brain anatomy, cerebral blood flow, and connectivity in the transition from PVs to MCS. Rev Neurosci. 2009;20:177-180. DOI: 10.1515/ revneuro.2009.20.3-4.177

63. Pallis C. Brainstem death: the evolution of a concept. Semin Thorac Cardiovasc Surg. 1990;2:135-152.

64. Chang C, Leopold DA, Scholvinck ML, Mandelkow $\mathrm{H}$, Picchioni D, Liu X, et al. Tracking brain arousal fluctuations with fMrI. Proc Natl Acad Sci. 2016;113(16):4518-4523. DoI: 10.1073/pnas.1520613113

65. Scammell TE, Estabrooke IV, McCarthy MT, Chemelli RM, Yanagisawa M, Miller MS, et al. Hypothalamic arousal regions are activated during modafinil-induced wakefulness. J Neurosci. 2000;20:8620-8628. DoI: 10.1523/jneurosci.20-22-08620.2000

66. Ogilvie RD. The process of falling asleep. Sleep Med Rev. 2001;5(3):247-270. DOI: 10.1053/smrv.2001.0145

67. Ashwal S, Cranford R. Medical aspects of the persistent vegetative state--a correction. The Multi-Society Task Force on PVs. N Engl J Med. 1995;333(2):130. DoI: $10.1056 /$ nejm199507133330216

68. The permanent vegetative state. Review by a working group convened by the Royal College of Physicians and 
endorsed by the Conference of Medical Royal Colleges and their faculties of the United Kingdom. J R Coll Physicians Lond. 1996;30:119-121.

69. Parvizi J, Damasio AR. Neuroanatomical correlates of brainstem coma. Brain. 2003;126(7):1524-1536. DoI: 10.1093/brain/awg166

70. Laureys S, Celesia GG, Cohadon F, Lavrijsen J, León-Carrión, J, Sannita WG, et al. Unresponsive wakefulness syndrome: a new name for the vegetative state or apallic syndrome. BMC Med. 2010;8(1):68. DoI: $10.1186 / 1741-7015-8-68$

71. Laureys S, Giacino JT, Schiff ND, Schabus M, Owen AM. How should functional imaging of patients with disorders of consciousness contribute to their clinical rehabilitation needs? Curr Opin Neurol. 2006;19(6):520-527. DoI: 10.1097/wco.0b013e3280106ba9

72. Laureys S, Pellas F, Van Eeckhout P, Ghorbel S, Schnakers C, Perrin F, et al. The locked-in syndrome: what is it like to be conscious but paralyzed and voiceless? Prog Brain Res. 2005;150:495-511. DOI: 10.1016/ s0079-6123(05)50034-7

73. Laureys S. The neural correlate of (un)awareness: lessons from the vegetative state. Trends Cogn Sci. 2005;9:556-559. DoI: 10.1016/j.tics.2005.10.010

74. Wijdicks EFM. Predicting the outcome of a comatose patient at the bedside. Pract Neurol. 2019. Dor: 10.1136/ practneurol-2019-002359

75. Laureys S, Bodart O, Gosseries O. The Glasgow Coma Scale: time for critical reappraisal? Lancet Neurol. 2014;13(8):755-757. DOI: 10.1016/s1474-4422(14)70152-8

76. Jennett B, Plum F. Persistent vegetative state after brain damage. A syndrome in search of a name. Lancet. 1972;4(1):734-737. DoI: 10.1016/s0020-1383(72)80031-7

77. Machado C, Estevez M, Carrick FR, Rodríguez R, Pérez-Nellar J, Chinchilla M, et al. Vegetative state is a pejorative term. NeuroRehabilitation. 2012;31(4):345347. DoI: 10.3233/nre-2012-00802

78. Machado C. Reader response: Disruption of the ascending arousal network in acute traumatic disorders of consciousness. Neurology. 2020;95(5):233-234. DOI: 10.1212/wnl.0000000000010097

79. Giacino J, Fins JJ, Machado A, Schiff ND. Central thalamic deep brain stimulation to promote recovery from chronic posttraumatic minimally conscious state: challenges and opportunities. Neuromodulation. 2012;15(4):339-349. DOI: 10.1111/j.15251403.2012.00458.x

80. Ueyama T, Shirataki K, Tamaki N. Traumatic basilar artery dissection presenting with "locked-in" syndrome: report of a case. No Shinkei Geka. 1996;24:1035-1039.
81. Wijdicks EF, Scott JP. Outcome in patients with acute basilar artery occlusion requiring mechanical ventilation. Stroke. 1996;27(8):1301-1303. DOI: 10.1161/01. str.27.8.1301

82. Wijdicks EF. The clinical determination of brain death: rational and reliable. Semin Neurol. 2015;35(2):103104. DOI: $10.1055 / \mathrm{s}-0035-1547531$

83. Giacino JT, Ashwal S, Childs N, et al. The minimally conscious state: definition and diagnostic criteria. Neurology. 2002;58(3):349-353. DOI: 10.1212/ wnl.58.3.506

84. Seel RT, Sherer M, Whytee J, Katz DI, Giacino JT, Rosenbaum AM, et al. Assessment scales for disorders of consciousness: evidence-based recommendations for clinical practice and research. Arch Phys Med Rehabil. 2010;91(12):1795-1813. DoI: 10.1016/j. apmr.2010.07.218

85. Laureys S, Boly M, Maquet P. Tracking the recovery of consciousness from coma. J Clin Invest. 2006;116(7):1823-1825. DOI: 10.1172/jci29172

86. Cruse D, Thibaut A, Demertzi A, Nantes JC, Bruno MA, Gosseries O, et al. Correction to: Actigraphy assessments of circadian sleep-wake cycles in the Vegetative and Minimally Conscious States. BMC Med. 2018;16(1):134. DOI: 10.1186/s12916-018-1139-y

87. Wielek T, Lechinger J, Wislowska M, Blume C, Ott P, Wegenkittl S, et al. Sleep in patients with disorders of consciousness characterized by means of machine learning. PLoS One. 2018;13(1):e0190458. DoI: 10.1371/ journal.pone.0190458

88. Machado C. The minimally conscious state: definition and diagnostic criteria. Neurology. 2002;59:1473-1474.

89. Wannez S, Gosseries O, Azzolini D, Martial C, Cassol $\mathrm{H}$, Aubinet $\mathrm{C}$, et al. Prevalence of coma-recovery scale-revised signs of consciousness in patients in minimally conscious state. Neuropsychol Rehabil. 2018;28(8):1350-1359. DOI: 10.1080/09602011.2017.1310656

90. Giacino JT, Kalmar K, Whyte J. The JFk Coma Recovery Scale-Revised: measurement characteristics and diagnostic utility. Arch Phys Med Rehabil. 2004;85:2020-2029.

91. Naccache L. Minimally conscious state or cortically mediated state? Brain. 2018;141(4):949-960. DoI: 10.1093/brain/awx324

92. Fischer DB, Boes AD, Demertzi A, Evrard HC, Laureys $\mathrm{S}$, Edlow $\mathrm{BL}$, et al. A human brain network derived from coma-causing brainstem lesions. Neurology. 2016;87(23):2427-2434. DOI: 10.1212/ wnl.0000000000003404 
93. Snider SB, Bodien YG, Bianciardi M, Brown EN, Wu $\mathrm{O}$, Edlow BL. Disruption of the ascending arousal network in acute traumatic disorders of consciousness. Neurology. 2019;93(13):e1281-e1287. DOI: 10.1212/ wnl.0000000000008163

94. Demertzi A, Van Ombergen A, Tomilovskaya E, Jeurissen B, Pechenkova E, Di Perri C, et al. Cortical reorganization in an astronaut's brain after long-duration spaceflight. Brain Struct Funct. 2016;221(5):28732876. DOI: 10.1007/s00429-015-1054-3

95. Bremer F. Cerveau “isolé” et pbysiologie du sommeil. CR Soc Biol (Paris). 1935;118:1235-1241.

96. Lindsley DB, Bowden JW, Magoun HW. Effect upon the EEG of acute injury to the brain stem activating system. Electroencephalogr Clin Neurophysiol. 1949;1(14):475-486. DoI: 10.1016/0013-4694(49)90221-7

97. Gottesmann C. The neurophysiology of sleep and waking: intracerebral connections, functioning and ascending influences of the medulla oblongata. Prog Neurobiol. 1999;59(1):1-54. DoI: 10.1016/s03010082(98)00094-X

98. Lewis A, Adams N, Chopra A, Kirschen MP. Use of Ancillary Tests When Determining Brain Death in Pediatric Patients in the United States. J Child Neurol. 2017;32(12):975-980. DoI: 10.1177/0883073817724697 
